\title{
JOGOS DIGITAIS EDUCACIONAIS, PRÁTICAS INTERDISCIPLINARES E PENSAMENTO COMPUTACIONAL: RELAÇÕES POSSÍVEIS
}

\author{
EDUCATIONAL DIGITAL GAMES, INTERDISCIPLINARY PRACTICES AND \\ COMPUTER THINKING: POSSIBLE RELATIONSHIPS
}

\begin{abstract}
Julio Cesar Naves Fernandes
Universidade Cruzeiro do Sul / Programa de Pós-Graduação em Ensino de Ciências e Matemática / Universidade Cruzeiro do Sul, juliocesarnaves@hotmail.com

\section{Ismar Frango Silveira}

Universidade Cruzeiro do Sul / Programa de Pós-Graduação em Ensino de Ciências e Matemática / Universidade Cruzeiro do Sul, ismar.silveira@cruzeirodosul.edu.br
\end{abstract}

\begin{abstract}
Resumo
É comum que as pessoas se utilizem do termo interdisciplinaridade quando por alguma razão, pretendem ultrapassar as fronteiras que cercam os limites da área em que se situam, ou ainda quando nos deparamos com um saber que não se encaixa em nada que já definimos anteriormente, ou seja, quando nos encontramos em uma situação que exige diferentes perspectivas do conhecimento. A crescente evolução dos recursos tecnológicos, aliada a características marcantes dos mesmos, como a portabilidade, adaptabilidade, pervasividade, interatividade, ubiquidade, entre outras, vem mostrando um grande potencial para promover sua utilização em muitos campos da Educação, entre os quais a Educação Matemática. A interdisciplinaridade pode ser o caminho que finalmente integre os campos da tecnologia e da educação, aproximando-os e trazendo os alunos mais próximos a situações da vida real em seus processos de aprendizagem. Entre as tecnologias digitais mencionadas, destacam-se os jogos digitais - embora os jogos físicos estejam presentes em sala de aula há muito tempo, os avanços tecnológicos permitiram que os jogos digitais venham ocupando papeis importantes no contexto educacional, convertendo-se atualmente em uma das principais tecnologias empregadas com fins educacionais. Nesse contexto, as competências do Pensamento Computacional se tornam um ferramental conceitual útil para se trabalhar com problemas mais próximos da nossa realidade, que em sua grande maioria envolvem saberes interdisciplinares. Nesse sentido, o presente artigo faz um arrazoado conceitual sobre interdisciplinaridade, de forma a gerar subsídios que permitam integrá-la a jogos digitais no desenvolvimento do Pensamento Computacional.
\end{abstract}

Palavras-chave: Interdisciplinaridade, Jogos Digitais, Matemática, Pensamento Computacional, Educação 


\begin{abstract}
It is a commonplace for people mention interdisciplinary studies when, for some reason, they want to go beyond the boundaries that surround the limits of their specific field of knowledge, or when we encounter some piece of knowledge that does not fit into anything that we have already defined previously, or even when we find ourselves in a situation that demands different perspectives of knowledge. The increasing evolution of technological resources, together with their remarkable characteristics, such as portability, adaptability, pervasiveness, interactivity, ubiquity, among others, has shown great potential to promote its educational use in many fields, among them Mathematics. Interdisciplinary studies can be the way by which the fields of technology and education could be finally integrated, bringing them closer, allowing students to deal with real-life situations in their learning processes. Among the digital technologies mentioned are the digital games - although physical games have been present in the classroom for a long time, technological advances have allowed digital games to occupy important roles in the educational context, becoming currently one of the technologies most used for educational purposes. In this context, the competences of Computational Thinking become a useful conceptual tool to work with problems closer to our reality, which in large part involve interdisciplinary knowledge. In this sense, this article presents a discussion on interdisciplinary studies, presenting some aspects under which they could subside Computational Thinking, when integrated to digital games.
\end{abstract}

Keywords: Interdisciplinary Studies, Digital Games, Mathematics, Computational Thinking, Education

\title{
Introdução
}

Várias são as possibilidades didáticas existentes quanto ao uso da interdisciplinaridade, e se associarmos ainda a possibilidade de aplicar tecnologias digitais em sala de aula, podemos adicionar ainda mais possibilidades a esse vasto leque. E por mais que barreiras existam, os currículos em voga no país admitem e estimulam a interdisciplinaridade, mesmo que sob um ponto de vista prático não se percebam muitos resultados mais concretos, com impactos efetivos no processo educacional.

Na literatura científica, são apresentadas diversas classificações para a temática e temáticas afins, com termos que induzem à confusão: multidisciplinaridade, pluridisciplinaridade, interdisciplinaridade e transdisciplinaridade. Muitas vezes não há uma clareza, por parte dos docentes, sobre as diferenças entre tais terminologias e o impacto de cada uma no fazer docente. Embora haja diferenças marcantes entre as abordagens (Dolle, J. M., 2015; Silveira, 2016; Souza e Pinho, 2017; Silva, Cusati e Guerra, 2018), este trabalho fará menção ao termo interdisciplinaridade de maneira abrangente para se referir ao conjunto de termos supracitados, guardadas as devidas diferenças.

Trabalhar de forma interdisciplinar vai além de solicitar que todos os professores abordem um mesmo tema em sala de aula, e sim, está em relacionar um determinado tema a todas as áreas do saber - ou ao menos a um conjunto delas, fazendo com que o 
conhecimento rotacione entre todas elas, de forma harmônica e comunicativa, trazendo o aluno mais perto de situações cotidianas. Assim, devem ser propostos problemas que transitem em mais de uma área do conhecimento, e que sua solução necessite de pensamento crítico e sistemático, e principalmente, perpassando todas as disciplinas do conjunto escolhido.

A interdisciplinaridade não dilui as disciplinas, ao contrário, mantém sua individualidade. Mas integra as disciplinas a partir da compreensão das múltiplas causas ou fatores que intervêm sobre a realidade e trabalha todas as linguagens necessárias para a constituição de conhecimentos, comunicação e negociação de significados e registro sistemático dos resultados. (BRASIL, 1999, p. 89)

Com isso percebemos que a interdisciplinaridade coloca um objetivo em comum como premissa básica, pois o diálogo entre os saberes nos aproxima de uma melhor compreensão e significação de situações trazidas do mundo real. Mesmo que para alguns, esse relacionamento possa ser utópico, não podemos negar o enriquecimento da compressão do indivíduo em relação ao mundo. E talvez o fator diferenciador está no fato da interdisciplinaridade forçar:

[...] os professores em integrar os conteúdos da história com os da geografia, os de química com os de biologia, ou mais do que isso, em integrar com certo entusiasmo no início do empreendimento, os programas de todas as disciplinas e atividades que compõem o currículo de determinado nível de ensino, constatando, porém, que, nessa perspectiva não conseguem avançar muito mais. (BOCHNIAK, p. 21, 1998)

Trabalhar dessa forma não é tarefa fácil, afinal, compreender como realizar ligações entre saberes de área distintas, interiorizar a importância desse planejamento, sair das abordagens didáticas tradicionais, buscar novas perspectivas e pontos de vista, enxergar além de um pensamento fragmentado e realizar investigações fora da zona de conforto, se torna uma tarefa de superação a cada novo projeto.

Porém, os Parâmetros Curriculares Nacionais, há duas décadas, já colocavam a necessidade e o peso de se trabalhar de forma interdisciplinar sobre os ombros dos educadores, pois este trabalho precisa "partir da necessidade sentida pelas escolas, professores e alunos de explicar, compreender, intervir, mudar, prever, algo que desafia uma disciplina isolada e atrai a atenção de mais de um olhar, talvez vários" (BRASIL, 1999, p. 88-89).

Não é pretensão da interdisciplinaridade modificar as estruturas curriculares, mas sim, representar uma proposta de abordagem didática que estimule os processos de aprendizagem em diferentes componentes curriculares em torno de uma proposta unificada. Utiliza-se para isso, de uma dinâmica diferente quanto à condução dos processos didáticos - e por isso a interação entre todos os componentes desse processo se torna tão importante. O êxito de propostas interdisciplinares requer o envolvimento de alunos e professores, mobilizando os processos de construção de conhecimento por meio de problemas relacionados a elementos curriculares que envolvem competências, conteúdos. Nesse sentido, prevê-se que todo o ambiente educacional contribua para a execução de propostas interdisciplinares. 
Como na escola o aprendizado é um resultado desejável, é o próprio objetivo do processo escolar, a intervenção é um processo pedagógico privilegiado. O professor tem o papel explícito de intervir e provocar nos alunos avanços que não correriam espontaneamente. (Frison, 2000 p. 129)

Sabendo da complexidade envolvendo a temática interdisciplinar, tanto na sua prática educacional, quanto a sua pretensão cientifica e os desafios a serem enfrentados, neste artigo enfatizamos a importância da Didática como balizadora e das Tecnologias Digitais como indutoras desse processo. Porém, ressalta-se aqui que não existe um modelo único a ser empregado em práticas interdisciplinares, visto que a realidade e o cotidiano tendem a criar novas condições, novos pensamentos e novos objetivos dentro da construção interdisciplinar (Costa; Cury, 2016).

\section{A Interdisciplinaridade e a Didática}

Embora existam diversas abordagens didáticas inovadoras, não podemos afirmar que exista uma única didática interdisciplinar, mesmo que muitas das vezes as práticas inovadoras estejam em constante contato com processos interdisciplinares.

Ainda que não possamos estabelecer uma definição única sobre a prática interdisciplinar, tendo em vista os variados conceitos aplicados por diversos autores, podemos colocar a interdisciplinaridade como uma alternativa à didática disciplinar normalizada, seja no campo do ensino ou no da pesquisa. Portanto, quando trabalhamos de forma interdisciplinar, os resultados podem variar de acordo com o desenvolvimento do projeto, mesmo que o desafio buscado seja o mesmo (Leis, 2005).

Para Santomé (1998),

[...] Não é apenas uma proposta teórica, mas sobretudo uma prática. Sua perfectibilidade é realizada na prática; na medida em que são feitas experiências reais de trabalho em equipe, exercitam-se suas possibilidades, problemas e limitações. É uma condição necessária para a pesquisa e criação de modelos mais explicativos desta realidade tão complexa e difícil de abranger. (Santomé, 1998, p. 67)

Nesse sentido, podemos então destacar a didática dentro do processo de formação do professor, pois como parte do currículo de formação, a didática "estuda os objetivos, os conteúdos, os meios e as condições do processo de ensino tendo em vista finalidades educacionais, que são sempre sociais" (LIBÂNEO, 1994, p.16). Por sua vez, a didática influencia diretamente os processos de ensino e aprendizagem, pois é por meio dela que se criam os laços entre os saberes, o relacionamento e a recepção dos alunos por com estes.

Permeia todos os outros, sendo interdisciplinar, pois será a "base comum" para que o professor busque a melhor forma de desenvolver sua função. Podemos perceber que é clara a importância da didática na formação e ação docente. (Baradel, 2007, p.36-37)

Fica a cargo do professor a responsabilidade de utilizar desse saber para relacionar a aprendizagem às situações e problemas sociais que permeiam o meio em que ambos estão inseridos. 
Sendo assim, uma vez que as estratégias didáticas tenham como premissa explorar as aprendizagens sociais, voltadas para a vida e não somente aos componentes curriculares previstos no ciclo escolar, o emprego adequado da interdisciplinaridade se torna um recurso valioso, pois apresenta um leque de recursos que podem contribuir nos processos de ensino e aprendizagem (Pimenta, 2001).

Para Fazenda (2002),

Interdisciplinaridade é uma nova atitude diante da questão do conhecimento, de abertura à compreensão de aspectos ocultos do ato de aprender e dos aparentemente expressos, colocando-os em questão. [...] A interdisciplinaridade pauta-se numa ação em movimento. Pode-se perceber esse movimento em sua natureza ambígua, tendo como pressuposto a metamorfose, a incerteza. (FAZENDA, 2002, p. 180)

A interdisciplinaridade, dentre suas características, é uma classificação para um determinado saber que se torna comum entre pelo menos duas disciplinas ou áreas do saber, o que permite uma relação recíproca entre os conhecimentos. O que nos leva a entender a composição o termo interdisciplinaridade, do qual o prefixo "inter" nos sugere os termos "entre", "dentro" e "em meio", enquanto o termo "disciplinar" segue a linha pedagógica, no sentido de instrução sobre determinada ciência. Ou seja, a forma pela qual as disciplinas interagem dentro dos currículos. (JAPIASSU, 1976).

Com isso acabamos por cair em duas distintas visões sobre a interdisciplinaridade. $\mathrm{Na}$ primeira delas temos um ponto de vista epistemológico, onde caímos em uma discussão relacionada às potencialidades e paradigmas sobre essa ciência, nas formas de se produzir o conteúdo interdisciplinar e principalmente no que se refere a conjuntura entre a realidade e o sujeito. Por conseguinte, temos um ponto de vista pedagógico, que se preocupa principalmente com a relação da interdisciplinaridade com os currículos, e sua metodologia.

Assim, o que diferencia a interdisciplinaridade da disciplinaridade, está na complexidade entre se criar uma relação entre todas as ramificações das grandes áreas do conhecimento, permitindo que cada saber único interaja de forma harmónica com a ideia proposta inicialmente. Novamente com isso percebemos a importância da didática nesse processo, que talvez seja o grande entrave no meio prático, tendo vista que as especializações fazem com que os docentes se prendam a determinada área, o que torna a interdisciplinaridade um desafio em seu planejamento.

\section{Tecnologia como indutor da Interdisciplinaridade}

Entende-se que a escola é o um ambiente que favorece a aprendizagem, a criação do conhecimento, ou até mesmo a reconstrução deste mesmo saber. Sendo assim, é necessário que esse meio acompanhe os avanços globais, se moldando às demandas do mundo contemporâneo e criando condições para a formação do aluno. Defendemos aqui o uso da interdisciplinaridade para a aproximação da aprendizagem por meio do rompimento, ainda que pontual e temporário, dos limites criados pelas disciplinas, proporcionando processos de construção de conhecimento mais amplos e aderentes à realidade. Porém, sabemos que didaticamente, ainda existem empecilhos no que se 
refere as estratégias e metodologias para aplicação da interdisciplinaridade. Sendo assim, é possível recorrer ao uso efetivo das tecnologias digitais em sala de aula, e compreender que é possível se utilizar de suas características e vantagens a favor da aprendizagem.

Certamente, nem todas as tecnologias existentes são relevantes para a educação, em especial tecnologias não-dedicadas a esse campo, que podem apresentar baixo potencial de aplicação educacional. Entretanto, no que se refere a tecnologias voltadas diretamente à educação, não podemos negar que possuem características importantes, permitindo que se possa "adquirir, organizar, armazenar, analisar, relacionar, integrar, aplicar e transmitir informação" (CHAVES, 2007, p.1) quando empregadas de maneira efetiva.

Ressaltamos que o uso das tecnologias digitais, principalmente no que se refere ao uso dos computadores (incluindo dispositivos móveis) e da Internet, vem modificando o cotidiano de muitas pessoas em todo mundo, de forma a se tornar atualmente um elemento essencial no seu dia a dia.

Souza e Souza (2010), defendem que,

A adaptação e absorção de novas tecnologias além de facilitar a aquisição de conhecimento cria certa criatividade, juízo de valor, aumento da autoestima dos usuários, além de permitir que adquiram novos valores e modifiquem o comportamento transformando as tarefas árduas, negativas e difíceis em algo dinâmico, positivo e fácil. (SOUZA e SOUZA, 2010, p.128)

A informática por sua vez, vem acompanhando e ditando o ritmo das mudanças, e se integrando cada vez mais com áreas distintas do saber, com impactos na vida cotidiana. Assim, gradativamente, as diversas áreas do conhecimento têm se utilizado das tecnologias em suas pesquisas, o que acaba por tornar estas altamente dependentes da tecnologia, devido às possibilidades de, por exemplo, permitir o processamento de grandes massas de dados, encurtar tomadas de decisões ou executar processos que manualmente seriam demasiadamente longos ou até irrealizáveis.

No que se refere à Educação, a tecnologia vem ganhando lenta e paulatinamente seu espaço. Ainda que aquém do esperado e mais vagarosamente do que em outras áreas da vida cotidiana, as tecnologias digitais vêm mostrando seu potencial de proporcionar novos panoramas à aprendizagem, para aqueles atores desse processo que delas estejam se apropriando.

O paradigma de que a escola é um lugar para se "passar conhecimento" não se sustenta. Em primeiro lugar, devido ao fato de que conhecimento não se passa, mas sim é um resultado, em contínua evolução, de um processo individual (a aprendizagem) em um contexto social, este proporcionado pela escola. A ela cabe propor condições para a execução exitosa desse processo, além de criar as condições necessárias para que, de forma crítica, o indivíduo busque soluções racionais, de forma interativa e social, para solucionar esses problemas. (SOUZA e SOUZA, 2010)

Nesse contexto, encontra-se o advento da Internet, que proporciona acesso a um grande volume de informações, que são transmitidas e modificadas em fluxos inimagináveis até há pouco tempo. Em um mundo em que a informação e o conhecimento 
estão rapidamente em mudança, utilizar dessa ferramenta como forma de tratar informações recentes no contexto dos processos de aprendizagem proporciona maior satisfação do aluno nessa busca. A própria forma de se estudar vem sendo modificada devido à Internet, pois ela permite dinâmicas de aprendizagem diferentes, considerando o maior acesso à informação e o estabelecimento de redes pessoais.

Se a internet e a tecnologia proporcionam acesso a informações, acontecimentos e fatos ao indivíduo, esse por sua vez, acaba por estar um passo a frente dos demais na sociedade, já que "manter-se se informado sobre os fatos e acontecimentos do mundo social é uma questão da sobrevivência, pois aprender sempre é algo inevitável para conseguir se conseguir um bom emprego e sucesso profissional". (SOUZA e SOUZA, 2010, p.133)

Prensky (2010, p.202), coloca que "o papel da tecnologia, em nossas salas de aula, é o de oferecer suporte ao novo paradigma de ensino", e ainda "apoiar os alunos no processo de ensinarem a si mesmos". O autor nos abre a visão de que o seu tradicional uso como recurso meramente expositivo, como é usado em muitas das vezes, não se enquadra nas novas propostas de estratégias ou metodologias de ensino, nas qual, do ponto de vista didático, o professor se torna um mediador, dando aos alunos as condições para que conduzam, eles mesmos, seus processos de construção do conhecimento.

Além disso, com todos os tipos de ferramentas tecnológicas existentes, para todas as áreas de conhecimento, é possível permitir que o conhecimento consiga caminhar sozinho, ou em uma forma menos abstrata, que os alunos consigam, com o auxílio dessas ferramentas, construir estruturas de raciocínio e compartilhá-las com outros indivíduos, desenvolvendo assim seu próprio saber. (CALEJON; SILVEIRA, 2019)

\section{Jogos Digitais Educacionais}

"Os jogos digitais podem ser definidos como ambientes atraentes e interativos que capturam a atenção do jogador ao oferecer desafios que exigem níveis crescentes de destreza e habilidades" (BALASUBRAMANIAN E WILSON, 2006, p. 17).

Os jogos estão presentes em sala de aula há muito tempo em suas versões ditas "físicas". Porém, com os avanços tecnológicos, os jogos digitais vêm ocupando esse papel, sendo uma das principais ferramentas tecnológicas utilizada para funções pedagógicas. Isso é percebido principalmente por conta do efeito motivador produzido pelos desafios proporcionados pelos jogos digitais (MUNGUBA et. al., 2003).

De acordo com Lima et. al. (2009), ao trazermos os jogos digitais para o cenário educacional, projetando-os com este fim, estes recebes a denominação de jogos educacionais. Deve-se ressaltar, neste ponto, que a simples inserção de um jogo no contexto educacional não é suficiente para que o jogo possa ser classificado como tal, por isso Pietro et. al. (2005, p. 10) observa que estes:

[...] devem possuir objetivos pedagógicos e sua utilização deve estar inserida em um contexto e em uma situação de ensino baseados em uma metodologia que oriente o processo, através da interação, da motivação e da descoberta, facilitando a aprendizagem de um conteúdo (PIETRO et. al, 2005, pag.10) 
Pelo exposto, algumas características devem ser adicionadas nesse cenário para que se possa considerar um Jogo Digital como educacional. O mapa mental da Figura $1 \mathrm{a}$ seguir sintetiza o que os autores supracitados dizem sobre cada característica, e como uma boa parte desses pesquisadores acaba por entrar em um consenso sobre muitos desses aspectos, pelo menos na qualidade intrínseca proporcionada por eles.

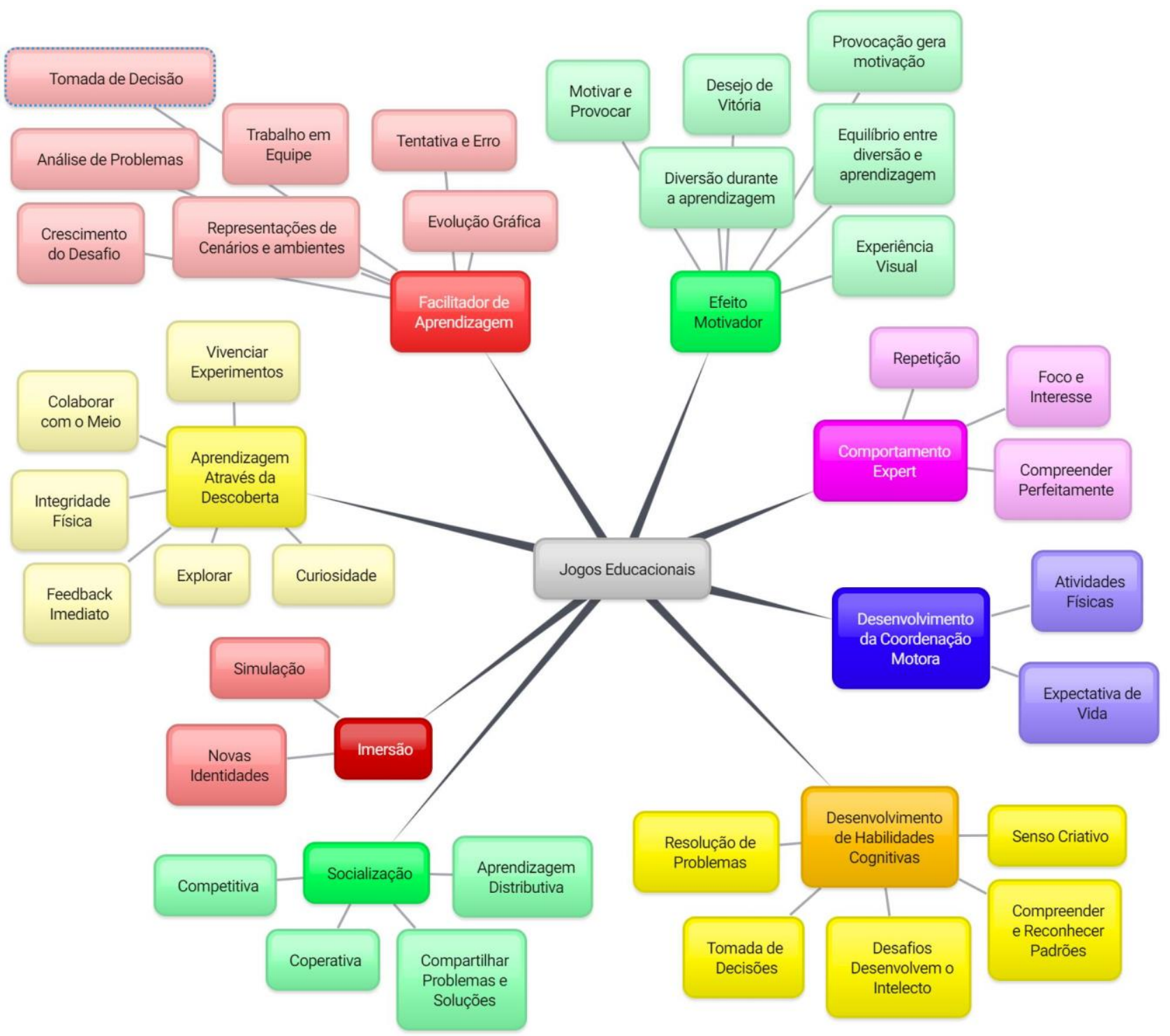

Figura 1 - Mapa mental das Características dos Jogos Educacionais Digitais - Fonte:

Autores

Há que se ressaltar, todavia, resistências quanto à adoção efetiva dos jogos educacionais. Silveira (2016) aponta um leque de fatores que variam desde a capacitação insuficiente dos professores para seu uso adequado e sua integração com o currículo, bem como dificuldades variadas de cunho técnico. Uma das barreiras em relação aos jogos digitais está relacionada ao período demasiadamente longo que geralmente são ocupados por eles, o que acaba gerando questionamentos entre os pais e professores, argumentando que o tempo dedicado aos os jogos poderia ser melhor aplicado com o estudo ou outras atividades. É seu desejo que os jovens se comprometam e concentrem- 
se nos estudos da mesma forma que o fazem com jogos (KIRRIEMUIR; MCFARLANE, 2004).

Nesse sentido, jogos digitais educacionais poderiam preencher essa lacuna, ao ter objetivos pedagógicos devidamente traçados, aliados aos aspectos lúdicos. Entretanto, como afirmam Barboza Jr. e Silveira (2016), jogos educacionais, de modo geral, falham nos quesitos de persuasão, motivação e engajamento. Outros problemas relacionam-se à complexidade na adaptação de jogos digitais educacionais em relação aos currículos prescritos, o que pode ser solucionado ao se adotar tecnologias abertas, como sugerem Silveira e Villaba-Condori (2018).

Por comodidade da leitura, a figura anterior será particionada nas figuras a seguir, em relação às características principais. A primeira característica, já citada anteriormente, é o que a maior parte dos autores chamam de efeito motivador.

Para Hsiao (2007), os jogos educacionais devem possuir um equilíbrio entre a diversão e a aprendizagem, e o que provoca a aprendizagem nesse caso são os ambientes gerados pelos jogos, tornando a aquisição desse conhecimento um ambiente interativo e dinâmico.

No âmbito dos jogos educacionais, Prensky (2001) e Hsiao (2007), concordam que a diversão é fundamental durante o processo de estudo, isso gera tranquilidade e uma maior recepção pelo conteúdo que será trabalhado na aprendizagem. Balasubramanian e Wilson (2006) colocam como ponto de provocação para a motivação as curiosidades geradas pelos enredos, os desafios provocados a cada nova etapa, a interação através da participação direta com o jogo e as fantasias geradas pelo jogo.

Já para Mitchell \& Savill-Smith (2004), a experiência visual é um fator muito importante para que o jogador se sinta imerso e ao mesmo tempo atraído pela aventura proporcionada durante o jogo. Outro fator que muitos autores acham importante é o que se convencionou denominar de estado de fluxo, a partir do trabalho inicial de Csikszentmihályi (1997).

Esse estado representa o equilíbrio ideal entre habilidades e desafios, que se não devidamente equilibrados podem levar a estados de ansiedade ou tédio. No contexto de jogos digitais, a aquisição de novas habilidades é em geral impulsionada pelo intenso desejo pela vitória. Jogos bem elaborados permitem que os jogadores cheguem a esse nível de desafio, onde o grau de desafio é equilibrado em relação às habilidades desenvolvidas.

No contexto de jogos educacionais, os desafios associados a componentes curriculares como motivadores e provocadores para promover o interesse no estudo já eram pontos defendidos por Ritchie e Dodge (1992). A Figura 2 detalha tais aspectos. 


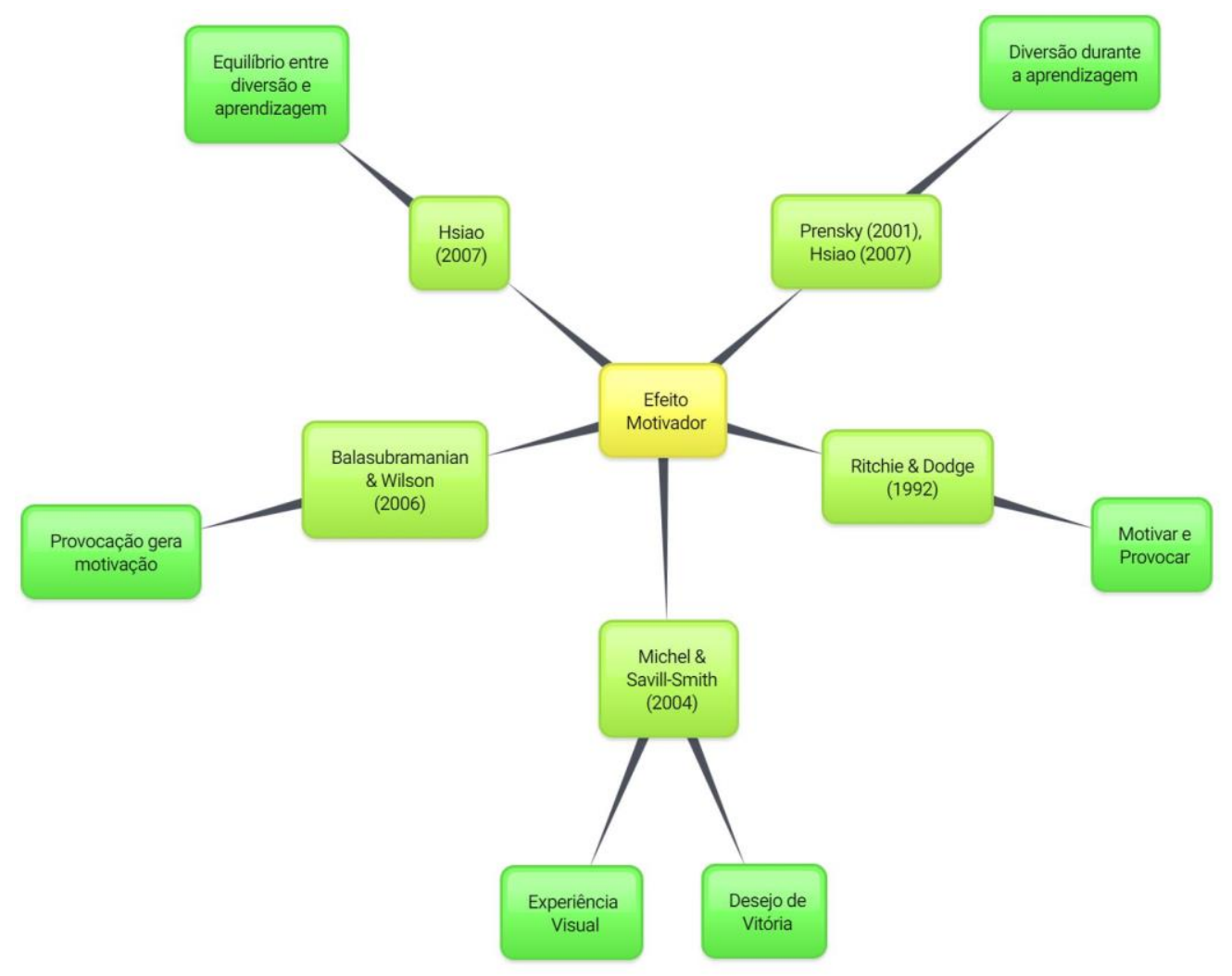

Figura 2 - Efeito Motivador nos Jogos Educacionais Digitais - Fonte: Autores

A discussão anterior nos leva à segunda característica dos jogos educativos, aqui chamada de facilitador do aprendizado. Os Jogos Digitais podem transitar entre as mais diferentes áreas do saber, além disso, os recursos gráficos, de Física e Inteligência Artificial disponíveis nos motores dos jogos, aliada à evolução das placas gráficas, que permitem processamento em tempo real ou muito próximo disto, permitem representações de cenários, situações e ambientes complexos. No contexto do Ensino de Ciências e Matemática, Fabricatore (2000), assim como Mitchell e Savill-Smith (2004) colocam a matemática e a ciências em evidência nesse processo, tendo em vista que alguns elementos não visíveis, como a própria estrutura do átomo, podem ser produzidos, ou então representações gráficas interativas na Matemática. Um ponto observado pelos últimos autores, no que se refere à característica de facilitar o processo de aprendizagem, está relacionada às decisões que os jogadores devem tomar durante o jogo, isso permite que se tenha uma aprendizagem por meio de tentativa e erro.

Kirriemuire e McFarlane (2004) colocam a importância de se atentar, durante o processo de elaboração e construção do jogo, no crescimento proporcional do desafio em relação a habilidade ou aprendizagem requerida, fazendo com que isso funcione de uma forma evolutiva. Gros (2003) lembra também que jogos que permitem uma plataforma multijogador, proporciona aprendizagens em grupo, trabalho em equipe e interação social. Ainda, Mitchell e Savill-Smith (2004) concordam que os principais benefícios que esse facilitador de aprendizagem proporciona está na melhoria das habilidades cognitivas e motoras, nas tomadas de decisão, em uma maior atenção e análise sobre os problemas, além das habilidades relacionadas à Informática em si. A Figura 3 a seguir sintetiza esta discussão. 


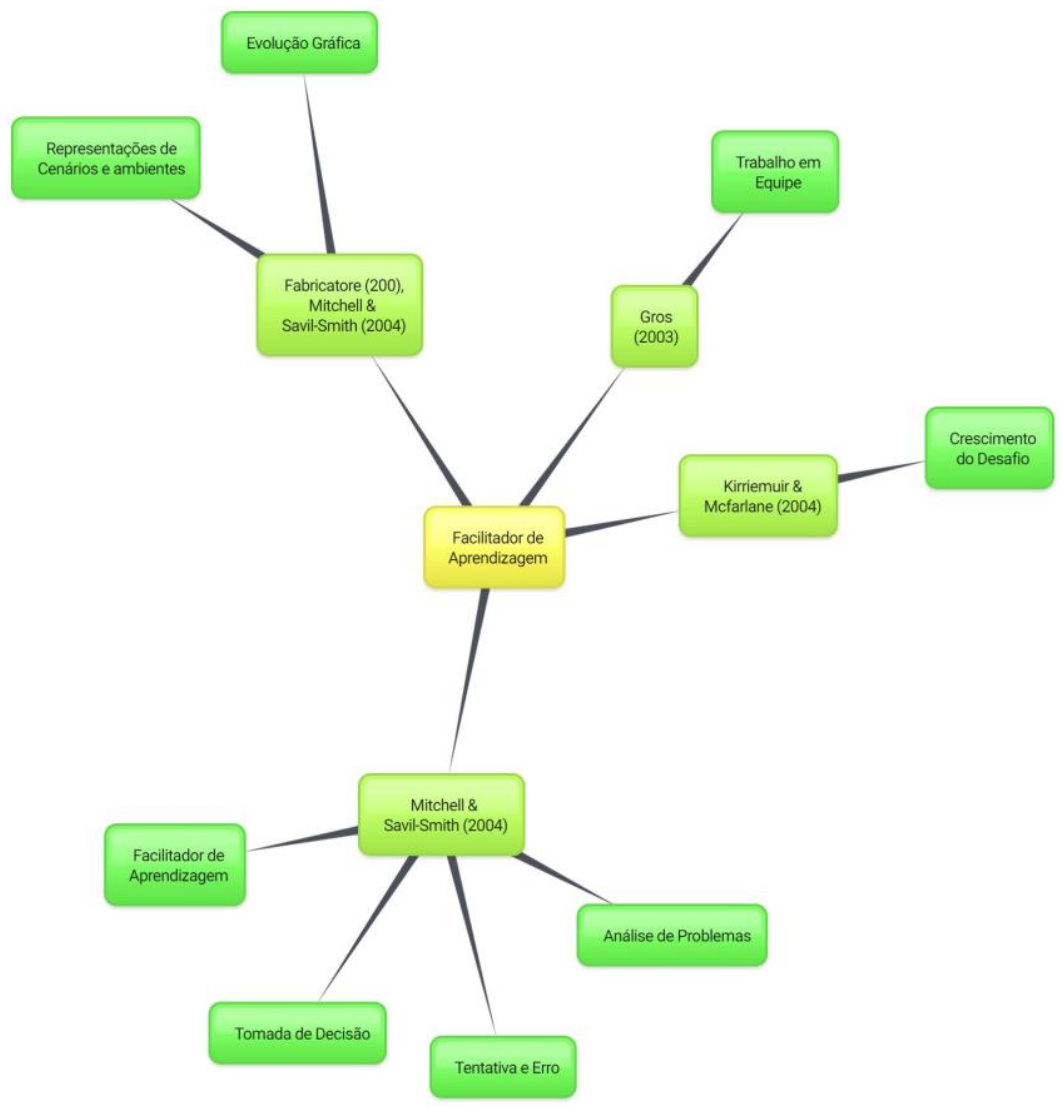

Figura 3 - Facilitador de Aprendizagem nos Jogos Educacionais - Fonte: Autores

Isso nos leva à terceira característica que deve estar presente nessas ferramentas, que é o desenvolvimento das habilidades cognitivas. Os desafios gerados pelos jogos aliados às decisões constantes, permitem e trabalham o desenvolvimento intelectual (GROS, 2003). Esse desenvolvimento intelectual está relacionado a outras habilidades que, para Balasubramanian e Wilson (2006), estão ligadas à resolução de problemas, além das habilidades de compreender e reconhecer padrões, senso criativo, processar as mais diversas formas como a informação é transmitida, culminando na tomada de decisões. A Figura 4 traz o mapa mental (parte da Figura 1) a respeito desta característica.

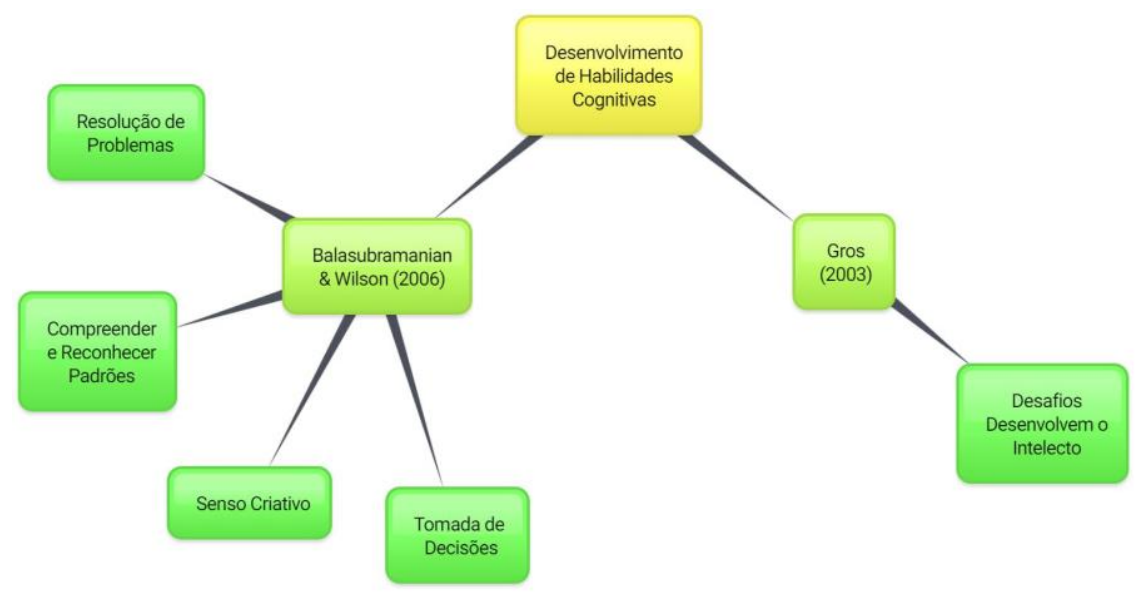

Figura 4 - Desenvolvimento de Habilidades Cognitivas nos Jogos Educacionais - Fonte: Autores 
A quarta característica está relacionada à aprendizagem através da descoberta. Para Becta (2001), os jogos devem proporcionar situações em que possa vivenciar experimentos e colaborar com o meio. Essas características são importantes para que, através da curiosidade, o jogador possa explorar ao máximo essas simulações, com um feedback imediato e livre de situações que possam colocar sua integridade em risco. (MITCHELL e SAVILL-SMITH, 2004), como representado na Figura 5.

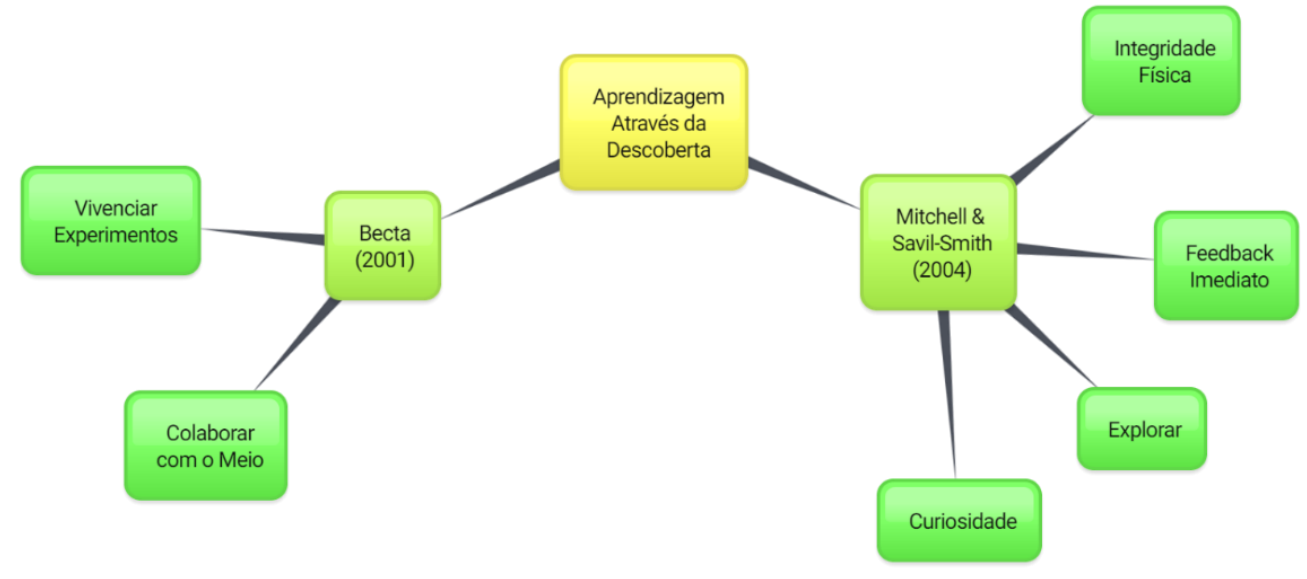

Figura 5 - Aprendizagem Através da Descobertas nos Jogos Educacionais - Fonte: Autores

A imersão provocada pelos jogos nos leva à quinta característica dos Jogos Digitais, por meio dos quais o jogador tem a possibilidade de experimentar novas identidades. Para Hsiao (2007), a imersão nos mais variados ambientes digitais proporciona ao jogador trabalhar e construir habilidades específicas geradas pelo personagem por ele controlado. De acordo com Weibel e Wissmath (2011), uma das principais razões para jogar jogos de computador é o prazer de estar imerso em um mundo mediado. Os simuladores, bem como jogos com alto grau de realismo (em especial os que se utilizam de interfaces de Realidade Virtual), permitem uma imersão ainda maior no universo dos personagens. Entretanto, há que se atentar ao que apontam Hamari et al. (2016), em cujo estudo não se encontraram evidências empíricas do impacto direto da imersão na aprendizagem, ainda que possa impactar o engajamento, este sim com impacto positivo direto. A Figura 6 resume parte desta discussão, baseando-se no que propõe Hsiao (2007).

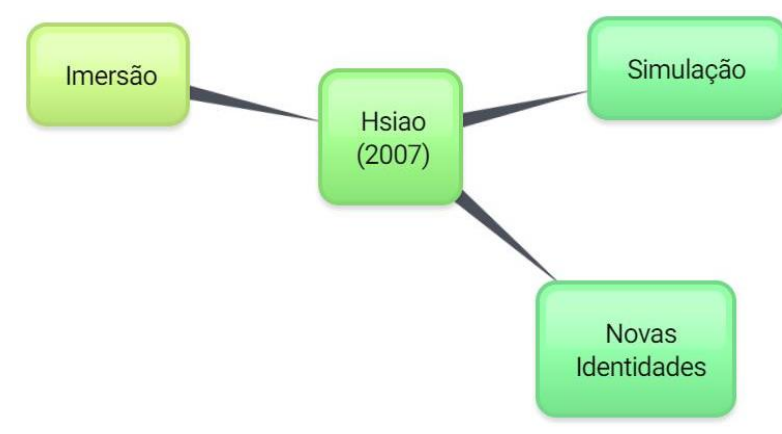

Figura 6 - Imersão nos Jogos Educacionais - Fonte: Autores 
A sexta características é a socialização. Seja de forma competitiva ou cooperativa, os Jogos Digitais permitem que os jogadores interajam de forma sociável, independente que essa interação ocorra por conta do jogo ou no ambiente físico em que o jogo ocorre. Segundo Hsiao (2007), quando se trabalha em grupo, é possível que os jogadores compartilhem ou exponham problemas e dificuldades, e que acabam por serem auxiliados pelos próprios colegas, essa ajuda nos traz a ideia de uma aprendizagem distributiva. Nesse sentido, a Figura 7, igualmente baseada em Hsiao (2007), apresenta uma esquematização deste aspecto.

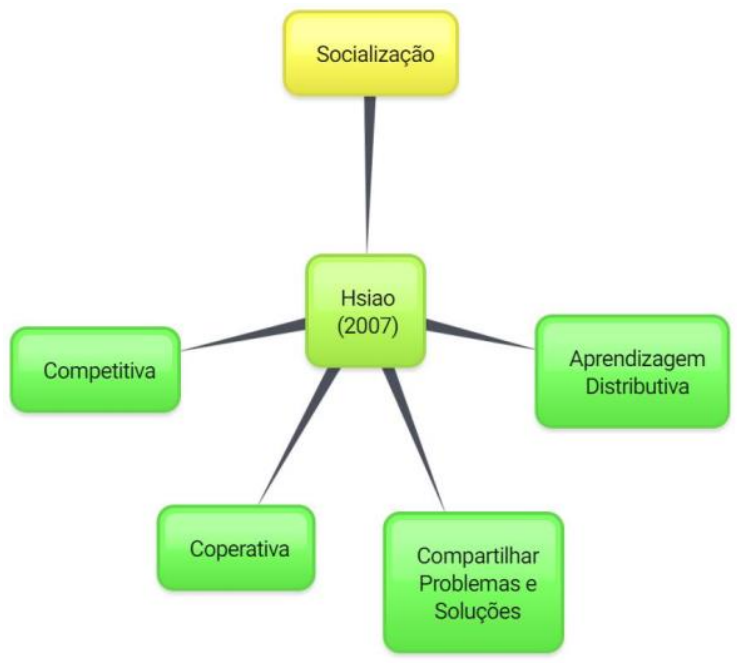

Figura 7 - Socialização nos Jogos Educacionais - Fonte: Autores

A sétima característica é a coordenação motora. Grande variedade de jogos permite o desenvolvimento da coordenação motora. Essa atividade é muito importante não apenas nos contextos de desenvolvimento inicial de funções motoras, como também em sua reabilitação. Essa última característica ganha importância com o público idoso, tendo em vista que a expectativa de vida da população tem aumentado no decorrer dos anos, e com um mundo globalizado, essas atividades se tornam essenciais, conforme exposto na Figura 8. (GROS, 2003).

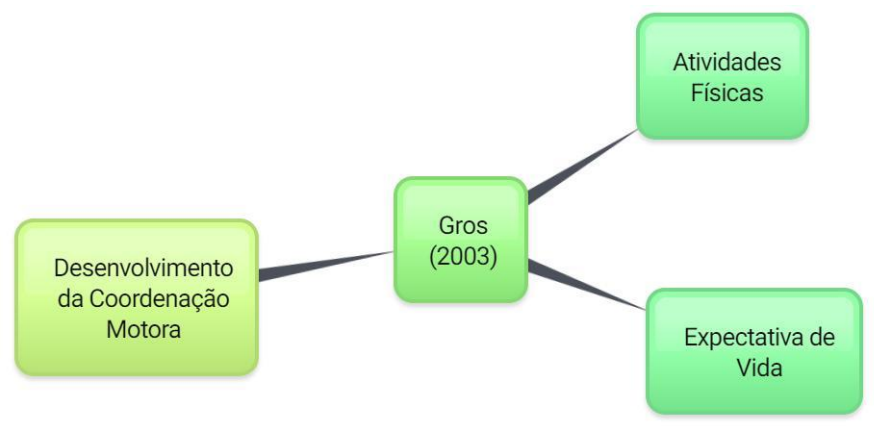

Figura 8 - Desenvolvimento da Coordenação Motora nos Jogos Educacionais - Fonte: Autores

E por fim chegamos a oitava e última característica, o comportamento expert (especialista). O termo expert nesse caso é utilizado como uma forma de denotar a capacidade em compreender perfeitamente, após um tempo, todas as propostas 
envolvidas durante o jogo. Para Vandeventer e White (2002), quando voltados a uma proposta educacional, os jogadores tendem a se tornar experts dentro da proposta do jogo, claro que para isso ocorra é necessário que o jogo possua ferramentas que mantenham o jogador focado e interessado no jogo. A Figura 9 exibe este aspecto.

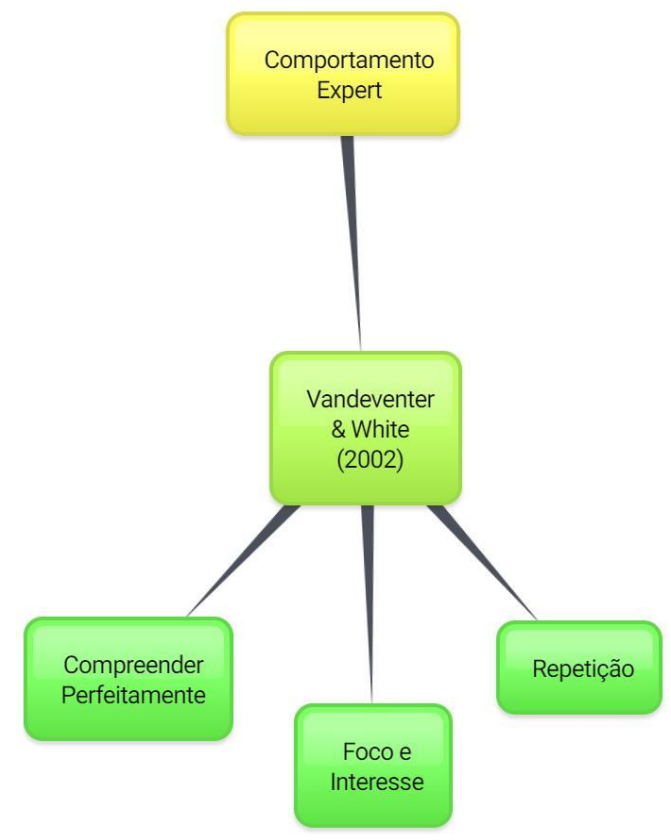

Figura 9 - Comportamento Expert nos Jogos Educacionais - Fonte: Autores

Encontrar um jogo que possua todas as oito características adequadamente implementadas é uma tarefa árdua, porém, todas elas possuem um potencial importante na aprendizagem e que podem trazer benefício quando aplicados em sala de aula.

Examinadas as principais características dos jogos educacionais, partimos agora para as principais definições relacionadas ao Pensamento Computacional, para em seguida estabelecermos relações entre esses três eixos norteadores deste capítulo.

\section{Pensamento Computacional}

A resolução de problemas sempre esteve relacionada diretamente com a utilização dos computadores, e por consequência, a computação também proporciona novos rumos para as áreas do conhecimento, adicionando uma nova forma de raciocinar. Isso se mostra ainda mais claro quando observamos suas aplicações em pesquisas relacionadas às mais variadas Ciências, que se utilizam da computação para alavancar resultados mais precisos e rápidos, do que se conseguiriam sem este (BARCELOS, 2012).

Para Wing (2006), o uso das ferramentas computacionais não é um privilégio apenas das Computação ou das demais Ciências e da Matemática, mas de outras áreas do conhecimento, que envolvem o cotidiano de todos nós.

[...] Por exemplo, uma criança arrumando a mochila para ir à escola, empacotando os itens que vai necessitar durante o dia, está criando um tipo de memória cache. Escolher a melhor fila no supermercado envolve 
conceitos de escalonamento de processos. Explicar como um telefone funciona mesmo na ausência de energia elétrica envolve conceitos de redundância e tolerância a falhas. (BAERCELOS, 2012, pag.37-38)

Wing (2006) coloca que o Pensamento Computacional é a forma de se referir as habilidades e competências da Computação que podem ser aproveitadas de forma relevante em áreas diversas do saber. Nesse contexto, a autora propõe as seguintes características importantes do Pensamento Computacional:

- Conceituar: Pensamento Computacional não está ligado a programar como algumas pessoas pensam. $O$ processo de resolução de problemas consiste em, a partir de problemas maiores, conseguir diluí-los em problemas menores, e para que isso ocorra, pensar além dos padrões convencionais ou então em níveis de abstração diferentes se torna necessário. Assim, não se trata apenas de construir soluções por meio da programação, mas sim em aprender a conceituar diferentes formas de se atacar um problema.

- Habilidade Fundamental: Novamente a autora se contrapõe ao paradigma que relaciona o Pensamento Computacional como habilidade mecânica. Ao contrário disso, o Pensamento Computacional apenas pode utilizar-se de computadores como ferramentas para a resolução de problemas diversos da nossa sociedade, e esse tipo de habilidade em tempos modernos se torna algo fundamental na vida das pessoas. Nesse sentido, defende-se que deve ser trabalhada essa habilidade nas escolas e demais espaços educacionais formais.

- Pensamento Humano: Solucionar problemas depende fundamentalmente dos mecanismos de construção e organização do pensamento. Realizar esta tarefa por meio de computadores requer que este raciocínio seja sistematizado para que possa ser processado em um computador. Assim, dado um problema, é necessário que se pense nas possíveis soluções do mesmo e, em seguida, sejam analisadas as possibilidades de automatizar alguma dessas soluções, de maneira total ou parcial, por meio da aplicação de ferramentas computacionais, e não o contrário.

- Complementa Matemática e Engenharia: O Pensamento Computacional proporciona uma forte ligação entre essas duas áreas, dando sentido e trazendo para o mundo real os problemas e suas soluções, preservando a suas particularidades.

- Produção de Ideias: O pensamento Computacional não tem como objetivo gerar um novo software ou hardware para cada problema, mas sim em saber utilizar as habilidades fundamentais para que, através de conceitos, se consiga ter em mãos diversas formas de se pensar em soluções de problemas em variados enredos e cotidianos.

- Em todos os lugares, para todas as pessoas: Aplicar Pensamento Computacional não exige necessariamente um dispositivo computacional físico, pois suas habilidades e competências estão ligadas ao raciocínio e a lógica, que são desenvolvidos por meio do pensamento analítico, crítico e sistêmico.

Ainda uma barreira na adoção dos princípios de Pensamento Computacional no Ensino de Ciência e Matemática é que ainda existe uma lacuna na aplicação desses princípios fora da área de Computação, em especial nos níveis inicias da Educação. 
Barcelos et al. (2015) realizaram uma revisão sistemática da literatura em relação ao Pensamento Computacional e a Matemática, e o mesmo concluiu que:

A maioria das experiências didáticas descritas tem como público-alvo os alunos da educação básica, mas uma parcela relevante das experiências foi desenvolvida com alunos de graduação. Por outro lado, há relatos insuficientes de experiências desenvolvidas para formação inicial e continuada de professores. Uma grande variedade de tópicos da Matemática vem sendo abordados, com alguma predominância para a Álgebra e o Cálculo. Vários estudos procuram desenvolver conjuntamente o Pensamento Computacional a Matemática por meio de habilidades de alto nível compartilhadas entre os dois paradigmas de pensamento, mas poucos estudos utilizam a construção e avaliação de modelos matemáticos e computacionais. (BAERCELOS, 2015, pag.1377)

Embora existam benefícios potenciais da aplicação dos princípios do Pensamento Computacional no contexto da Matemática, é necessário se questionar como os conteúdos tradicionais podem ser afetados pelo seu desenvolvimento. Entretanto, quando pensamos na relação do Pensamento Computacional com o desenvolvimento de jogos, vemos uma oportunidade de se alinhar outras áreas de conhecimento, a fim de se explorar ainda mais essas competências e habilidades, além de se criar a oportunidade de se criar um vínculo entre várias dessas áreas.

\section{Um elo pela Educação}

Os currículos escolares devem incentivar o desenvolvimento de habilidades que permitam ao indivíduo participar de forma ativa em seu meio social. Essas habilidades transitam entre os diversos campos do conhecimento, e vão desde funções motoras e cognitivas, até a resolução de problemas, o pensamento crítico e o raciocínio lógico (ZAHARIJA et al., 2013; NUNES, 2011). A grande questão a ser observada aqui então está em como as tecnologias podem ser alinhadas às metodologias e práticas educacionais, bem como às distintas teorias de aprendizagem, para que o processo de desenvolvimento dessas habilidades possa ser ampliado.

Se por um lado percebemos a necessidade do desenvolvimento de habilidades que possam ajudar a promover o conhecimento, por outro, sentimos a necessidade de fazer com que se estabeleçam sentidos no uso das tecnologias para promover essas competências. O Pensamento Computacional, dentre seus vários objetivos, visa o desenvolvimento de habilidades voltadas ao raciocínio e resolução de problemas, principalmente quando se utiliza da conceitualização e da representação sistêmica desses problemas. Essa necessidade parte do princípio de que durante nossa vida, teremos que fazer o uso dessas habilidades, não só por necessidade individual, mas também por conta que vivemos em um coletivo (VALENTE, 2003).

Essa situação é a representação de que os saberes precisam possuir uma ligação com a nossa vida, e a interdisciplinaridade tem exatamente esse papel. Aproximar os saberes, permitindo-se navegar entre os mais variados problemas sociais, tendo em vista que esses problemas não têm a sua solução restrita aos limites de uma única área do conhecimento, e que muitas das vezes, esses problemas podem fazer parte do cotidiano 
do indivíduo. A Figura 10 a seguir sintetiza esse raciocínio em um mapa mental, tendo a Educação como elemento central, ramificada nos três elementos cobertos por este trabalho: Interdisciplinaridade, Jogos Digitais e Pensamento Computacional.

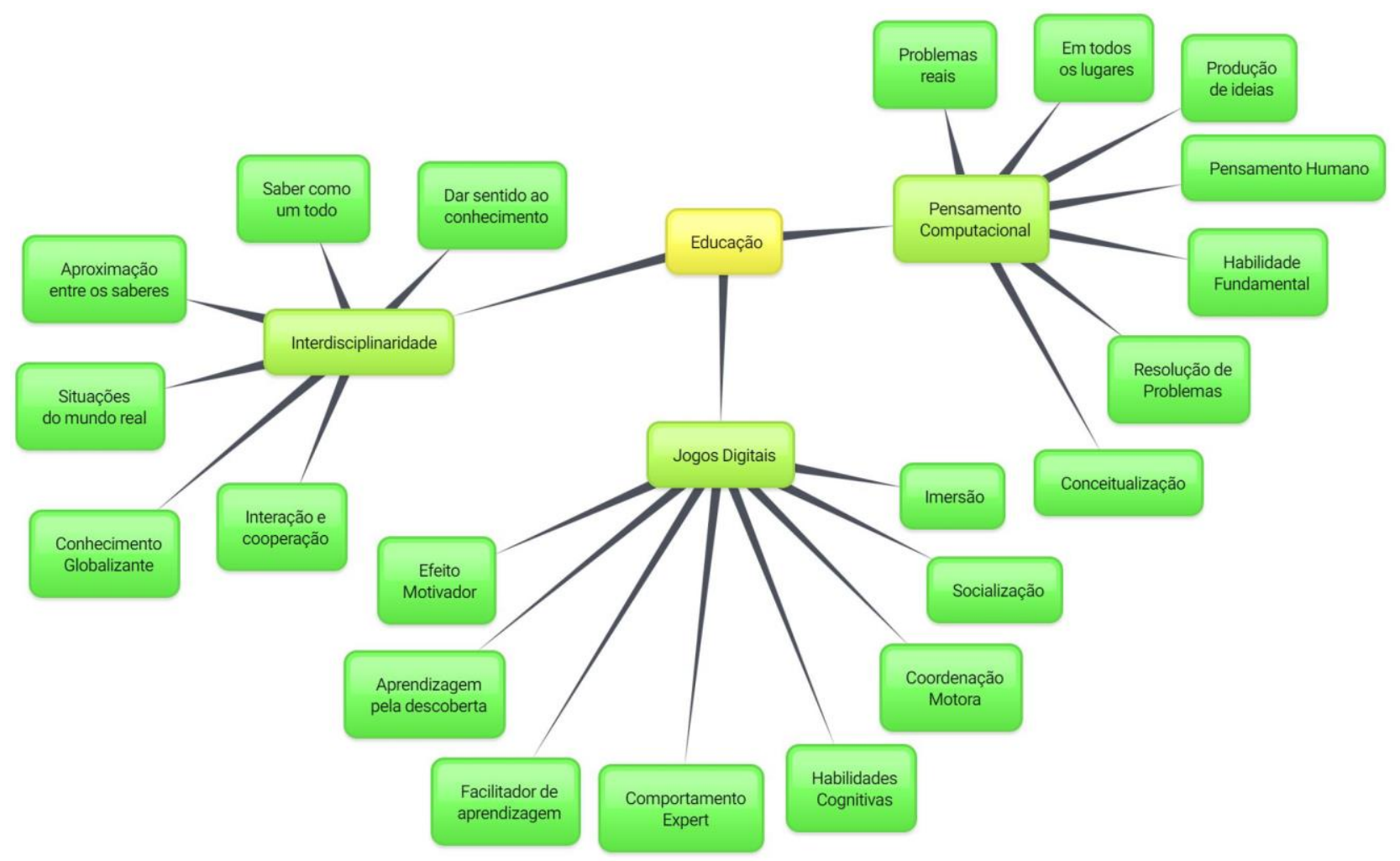

Figura 10 - Habilidades voltadas para a educação - Fonte: Autores

Embora tudo isso possa nos ser claro, a forma como se trabalhar a interdisciplinaridade ainda é motivo de discussão entre os pesquisadores e educadores. $E$ é nesse momento que as tecnologias computacionais, como os jogos digitais educacionais mencionados neste trabalho, apontam como um possível caminho como elementos integradores entre as habilidades do Pensamento Computacional e práticas interdisciplinares. Suas características proporcionam tal elo, pois a socialização, a descoberta e o desenvolvimento de habilidade cognitivas e motoras se tornam mais marcantes quando impulsionadas por um efeito motivador, e da imersão a um cenário ou situação que possa ser atrativa ou comum ao indivíduo.

A interdisciplinaridade busca ligar o que em algum momento foi perdido pela fragmentação dos saberes, mas em nenhum momento se opõe a uma organização disciplinar, pois sabe que estas carregam características próprias e únicas a elas. Com isso é importante destacarmos que o fator de aprendizagem que os jogos proporcionam não são dependentes da Educação, a aprendizagem é uma característica própria dos Jogos. Para Koster (2005), a capacidade de cada pessoa em superar os obstáculos e desafios proporcionados pelos jogos está diretamente relacionada à capacidade de aprender a superá-los, ou seja, quando nos deparamos com um problema, e aprendemos uma forma de vencer esse problema, acabamos por gerar um novo conhecimento por meio do jogo. 


\section{Considerações Finais}

Se trabalhar de forma interdisciplinar é uma tarefa árdua, o que exige que as pessoas envolvidas nesse processo deixem a sua zona de conforto. Reestruturar metodologias de ensino tradicionalmente estabelecidas e saberes adquiridos ao longo da vida também não é algo trivial, mas as mudanças provocadas e ditadas pelas tecnologias digitais impõem o repensar de práticas educacionais. A Didática realiza a união entre a teoria e a prática, enquanto a interdisciplinaridade promove a interação e proporciona novos ângulos de vista sobre um mesmo problema.

Nesse artigo pudemos observar que os Jogos Digitais têm grande potencial como estimuladores para o senso criativo, desde que projetados de como a conseguir prender a atenção do jogador, o que acaba mobilizando a concentração. Outras funções cognitivas como a imaginação, memória e em especial a criatividade, também podem ser trabalhadas. Alguns jogos também trabalham a coordenação motora, principalmente após a chegada dos dispositivos que utilizam reconhecimento de movimento, aliados ao suporte a Realidade Virtual e Aumentada. Porém, mesmo com todas essas possibilidades, é necessário que o professor esteja a par de como aproveitar dessas possibilidades múltiplas de interatividade, e como aliá-las a propostas interdisciplinares de aprendizagem.

E com isso, o Pensamento Computacional acaba por aparentar ser um bom elo de ligação entre os jogos digitais e propostas interdisciplinares clareira nesse processo, já que suas competências alinham a construção do pensamento sistêmico de forma transversal. A cultura digital faz com que novos elementos emerjam, e a necessidade de se trabalhar esses elementos desde cedo tendem a criar uma reação em cadeia, permitindo não apenas que a tecnologia venha a proporcionar cada vez mais ferramentas a favor da educação, mas também que os fundamentos epistemológicos por trás dos conceitos computacionais possam servir como novos balizadores de processos de aprendizagem alinhados com as demandas da contemporaneidade.

\section{Referências}

BALASUBRAMANIAN, Nathan; WILSON, Brent G. Games and Simulations. In: Society for information technology and teacher education International conference, 2006. Proceedings. v.1. 2006. Disponível em: http://www.coulthard.com/library/Files/ balasubramanianwilson_2005-gamesandsimulations.pdf. Acesso em: 28 mai. 2019.

BARADEL, C. de. B. Didática: contribuições teóricas e concepções de professores. 2007. 65f. Monografia - Universidade Estadual Paulista. Faculdade de Ciências, Campus Bauru, 2007.

BARBOZA JR, A. T.; SILVEIRA, I. F. PerMotivE: Um Modelo conceitual de Persuasão, Motivação e Engajamento para Jogos Educacionais. XV Simpósio Brasileiro de Jogos Digitais e Entretenimento (SBGAMES), São Paulo, p. 920-929, 2016. 
BARCELOS, T. S. SILVEIRA, I. S. Pensamento Computacional e Educação Matemática: Relações para o Ensino de Computação na Educação Básica. In: XX WorkShop sobre Educação em Computação, Curitiba, 2012.

BARCELOS, T. S. et al. Relações entre o Pensamento Computacional e a Matemática: uma Revisão Sistemática da Literatura. Anais dos Workshops do IV Congresso Brasileiro de Informática na Educação. 2015. Disponível em: http://www.brie.org/pub/index.php/wcbie/article/view/6311/4420. Acesso em: 28 mai. 2019.

BECTA. Computer Games in Education Project. Coventry: BECTA, 2001.

BOCHNIAK, R. Questionar o conhecimento: interdisciplinaridade na escola. 2 Edição. Editora Loyola. Soa Paulo, 1998.

BRASIL. Ministério da Educação. Secretaria de Educação Média e Tecnológica. Parâmetros Curriculares Nacionais: Ensino Médio. Brasília: Ministério da Educação, 1999.

CALEJON, L. M. C. SILVEIRA, I. F. Os Desafios da Educação Escolar na Contemporaneidade: Tecnologias da Informação e da Comunicação na Educação Escolar. REnCiMa, v. 10, n. 1 p.130-143, 2019. Disponível em: http://revistapos.cruzeirodosul.edu.br/index.php/rencima/article/view/2254/1098. Acesso em: 28 mai. 2019.

CHAVES, Eduardo O. C. Tecnologia na Educação. 2004. Disponível em: http://www.chaves.com.br/TEXTSELF/EDTECH/tecned2.htm. Acesso em: 28 mai. 2019.

COSTA, D. K. CURY, H. N. Mapeamento de Pesquisas Interdisciplinares no Rio Grande do Sul: Contribuição ao Diálogo entre Disciplinas. REnCiMa, v. 7, n. 1 p.59-73, 2016.

Disponível

em: http://revistapos.cruzeirodosul.edu.br/index.php/rencima/article/view/1084/ 810. Acesso em: 28 mai. 2019.

CSIKSZENTMIHALYI, M. Flow and the psychology of discovery and invention. HarperPerennial, New York, v. 39, 1997.

DOLLE, J. M. Multidisciplinaridade, interdisciplinaridade e transdisciplinaridade à luz da Epistemologia Genética. Revista Schème - Revista Eletrônica de Psicologia e Epistemologia Genéticas, v.7 n. 1, p. 4-31, 2015.

FABRICATORE, C. Learning and videogames: An unexploited synergy. In: International Conference of the Association for Educational Communications and Technology, Denver, Colorado. 2000.

FAZENDA, I. Dicionário em construção: interdisciplinaridade. São Paulo: Cortez, 2002.

FRISON, L. M. B. A Perspectiva do especialista em educação: um olhar sobre a Orientação Educacional: avanços e possibilidades. Santa Cruz do Sul: UNISC, set/dez, 2000.

GROS, B. The impact of digital games in education. First Monday, v. 8, n. 7, jul. 2003. Disponível em: http://www.firstmonday.org/issues/issue8_7/xyzgros/index.html. Acesso em: 28 mai. 2019. 
HAMARI, J. et al. Challenging games help students learn: An empirical study on engagement, flow and immersion in game-based learning. Computers in human behavior, v. 54, p. 170-179, 2016.

HSIAO, H. A Brief Review of Digital Games and Learning. DIGITEL 2007, The First IEEE International Workshop on Digital Game and Intelligent Toy Enhanced Learning. Los Alamitos, CA, USA: IEEE Computer Society, 2007. 124-129 p. Disponível em: http://doi.ieeecomputersociety.org/10.1109/DIGITEL.2007.3. Acesso em: 28 mai. 2019.

JAPIASSU, H. Interdisciplinaridade e patologia do saber. Rio de Janeiro: Imago, 1976.

KIRRIEMUIR, J. MCFARLANE, A. Literature review in games and learning. Futurelab Series Report, 8. University of Bristol. 39 p. 2004.

KOSTER, R. A Theory of Fun for Game Design. 2005.

LEIS, H. R. Sobre o Conceito de Interdisciplinaridade. Caderno de Pesquisa Interdisciplinar em Ciências Humanas. Agosto, 2005.

LIBÂNEO, J. C. Didática. 22ª ed. São Paulo: Cortez, 1994.

LIMA, M. C. F. et al. Jogos educativos no âmbito educacional: um estudo sobre o uso de jogos no projeto MAIS da Rede Municipal do Recife, 2009.

MITCHELL, A. SAVILL-SMITH, C. The use of computer and video games for learning: A review of the literature. Londres: Learning and Skills Development Agency (LSDA), 2004. Disponível em: htttp://www.lsda.org.uk/files/PDF/1529.pdf. Acesso em: 28 mai. 2019.

MUNGUBA, M. C. et al. Jogos Eletrônicos: Apreensão de Estratégias de Aprendizagem. Revista Brasileira em Promoção da Saúde. V. 16. N. 1. 2003. Disponível em: https://periodicos.unifor.br/RBPS/article/view/330/2032. Acesso em: 28 mai. 2019.

NUNES, D. J. Ciência da Computação na Educação Básica. Jornal da Ciência. 09 de setembro, 2011.

PRIETO, L. M. et al. Uso das Tecnologias Digitais em Atividades Didáticas nas Séries Iniciais. Renote: revista novas tecnologias na educação, Porto Alegre, v. 3, n. 1, p.1-11, maio 2005. Disponível em: http://www.cinted.ufrgs.br/renote/maio2005/artigos/ a6_seriesiniciais_revisado.pdf. Acesso em: 28 mai. 2019.

PIMENTA, S. G. Panorama atual da didática no quadro das ciências da educação: educação, pedagogia e didática. Pedagogia, ciência da educação? 3. ed. São Paulo: Cortez, 2001.

PRENSKY, M. Digital game-based learning. New York: McGraw-Hill, 2001.

PRENSKY, M. O papel da tecnologia no ensino e na sala de aula. Tradução Cristina M. P. In Conjectura, Caxias do Sul, v. 15, n. 2, p.201-204, maio/ago. 2010. Disponível em http://www.ucs.br/etc/revistas/index.php/conjectura/article/view/335/289. Acesso em: 28 mai. 2019.

RITCHIE, D. DODGE, B. Integrating Technology Usage across the Curriculum through Educational Adventure Games. p.10. Houston. 1992 
SANTOMÉ, J. T. Os motivos no currículo integrado. Capítulo II. Globalização e interdisciplinaridade: o currículo integrado. Porto Alegre: Artmed, 1998.

SILVA, A. X., CUSATI, I. C, GUERRA, M. G. G. V. Interdisciplinaridade e transdisciplinaridade: dos conhecimentos e suas histórias. RIAEE - Revista IberoAmericana de Estudos em Educação, v. 13, n. 3, p. 979-996, 2018.

SILVEIRA, I. F. A "multiplurintertransdisciplinaridade" da Informática na Educação. Computação Brasil n. 36, p. 40-46. Disponível em http://www.sbc.org.br/images/ flippingbook/computacaobrasil/computa_31/Comp_Brasil_02_2016.pdf. Acesso em 9 jun. 2019.

SILVEIRA, I. F.. Open educational games: Challenges and perspectives. In: 2016 XI Latin American Conference on Learning Objects and Technology (LACLO). IEEE, 2016. p. $1-9$.

SILVEIRA, I. F.; VILLALBA-CONDORI, K. O. An Open Perspective for Educational Games. Journal of Information Technology Research (JITR), v. 11, n. 1, p. 18-28, 2018.

SOUSA, J. G., PINHO, M. J. Interdisciplinaridade e transdisciplinaridade como fundamentos na ação pedagógica: aproximações teórico-conceituais. Revista Signos, v. 38, n. 2, p. 93-110, 2017.

SOUZA, I. M. A. SOUZA, L. V. A. O Uso da Tecnologia como Facilitadora da Aprendizagem do Aluno na Escola. Fórum Identidades, Itabaiana, v. 8, n. 4, p.127-142, jul./dez. 2010. Disponível em: http://200.17.141.110/periodicos/revista_forum_identidades/ revistas/ARQ_FORUM_IND_8/FORUM_V8_08.pdf. Acesso em: 28 mai. 2019.

VALENTE, J. A. Pesquisa, comunicação e aprendizagem com o computador. Série Pedagogia de Projetos e Integração de Mídias - Programa Salto para o Futuro, setembro, 2003.

VANDEVENTER, S. S. WHITE, J. A. Expert Behavior in Children's Video Game Play. Simulation Gaming, v. 33, n. 1, p. 28-48, 2002. Disponível em: http://sag.sagepub.com/cgi/content/abstract/33/1/28. Acesso em: 28 mai. 2019.

WEIBEL, D.; WISSMATH, B. Immersion in computer games: The role of spatial presence and flow. International Journal of Computer Games Technology, v. 2011, p. 6, 2011.

WING, J. M. Computational thinking. Communications of the ACM, v. 49, n. 3, p. 33-35, mar 2006.

ZAHARIJA, G.; MLADENOVIC, S.; BOLJAT, I. Introducing basic Programming Concepts to Elementary School Children, Procedia - Social and Behavioral Sciences, vol. 106, pp. 1576-1584. 2013. 